\title{
ANALGESIC EFFICACY OF INTRAPERITONEAL TRAMADOL VS. PLACEBO FOR POSTOPERATIVE PAIN RELIEF FOLLOWING LAPAROSCOPIC APPENDICECTOMY: A DOUBLE BLINDED ONE YEAR RANDOMIZED CONTROL TRIAL: SINGLE CENTRIC, HOSPITAL BASED STUDY
}

\author{
Vivek Pratap1, Anilkumar Parappa Bellad²
}

${ }_{1}^{1}$ Post Graduate Student, Department of Surgery, Jawaharlal Nehru Medical College, Nehru Nagar, Belgaum. ${ }^{2}$ Associate Professor, Department of Surgery, Jawaharlal Nehru Medical College, Nehru Nagar, Belgaum.

ABSTRACT
CONTEXT
Early postoperative pain is common and predominant complaint which results in prolonged hospital stay.

\section{AIMS}

The present study explores effectiveness of intraperitoneal instillation of tramadol on postoperative pain relief and emergence of adverse effects following laparoscopic appendectomy.

\section{SETTINGS AND DESIGN}

The present one year double blinded randomized controlled trial was done in the Department of General Surgery, KLES Dr. Prabhakar Kore Hospital and Medical Research Centre, Belgaum, from January 2014 to December 2014.

\section{METHODS AND MATERIAL}

A total of 60 patients undergoing elective laparoscopic appendectomy were enrolled. The selected patients were divided into two groups of 30 each as group A and B based on the drugs that is intraperitoneal tramadol $150 \mathrm{mg}$ (Diluted in $40 \mathrm{~mL}$ of normal saline) and $40 \mathrm{~mL}$ of intraperitoneal normal saline respectively.

\section{STATISTICAL ANALYSIS USED}

The categorical data was expressed as rates, ratios and percentages and comparison was done using Fisher's exact test and chisquare test. Continuous data was expressed as mean \pm standard deviation and the comparison was done using independent sample ' $t$ ' test. A probability (' $p$ ' value) of less than or equal to 0.05 at $95 \%$ confidence interval was considered as statistically significant.

\section{RESULTS}

In group $A, 53.33 \%$ of the patients were males compared and $46.67 \%$ in group $B(p=0.606)$. The mean age in group $A$ (26.13 \pm 9.96 years) and group B $(31.43 \pm 14.81$ years) were comparable $(p=0.110)$. Both the groups were comparable in terms of demographic characteristics, clinical presentation and vitals ( $p>0.050)$. The mean VAS scores at beginning were significantly low in group A $(1.53 \pm 0.94)$ compared to group B $(2.93 \pm 1.17)$ and similar trend was noted at all the durations through the post-operative period $(\mathrm{p}<0.001)$. Most of the patients in group A did not request for the post-operative analgesia $(56.67 \%$ vs $6.67 \%$; $p=0.011)$. In group A, significantly lower numbers of mean doses were administered $(0.57 \pm 0.82$ vs $2.20 \pm 0.92 ; \mathrm{p}<0.001)$. The frequency of postoperative rescue analgesia significantly low in group A at 15 minutes, 30 minutes, 6 hours and 12 hours as compared to group B $(p<0.050)$. Adverse events were noted in $23.33 \%$ of the patients with group A compared to $10 \%$ in group B ( $p=0.166)$. The mean hospital stay in group A was significantly low ( $\mathrm{p}=0.017)$.

\section{CONCLUSIONS}

Intraperitoneal instillation of tramadol offers effective post-operative visceral pain relief in laparoscopic appendectomy and incidence of adverse effects is well acceptable.

\section{KEYWORDS}

Intraperitoneal Instillation; Laparoscopic Appendectomy; Post-Operative Pain; Tramadol.

HOW TO CITE THIS ARTICLE: Pratap V, Bellad AP. Analgesic efficacy of intraperitoneal tramadol vs. placebo for postoperative pain relief following laparoscopic appendicectomy: a double blinded one year randomized control trial: single centric, hospital based study. J. Evolution Med. Dent. Sci. 2016;5(39):2390-2397, DOI: 10.14260/jemds/2016/556

Financial or Other, Competing Interest: None.

Submission 29-03-2016, Peer Review 27-04-2016,

Acceptance 03-05-2016, Published 16-05-2016.

Corresponding Author:

Dr. Vivek Pratap,

Post Graduate Student,

Department of General Surgery,

Jawaharlal Nehru Medical College,

Nehru Nagar, Belgaum-590010,

Karnataka, India.

E-mail: rvpsc@ymail.com

DOI: $10.14260 /$ jemds $/ 2016 / 556$

\section{INTRODUCTION}

Acute appendicitis is inflammation of the vermiform appendix and remains the most common cause of the acute abdomen in young adults. ${ }^{1}$ It is a common condition regarded as a surgical emergency, though notoriously difficult to diagnose and associated with a variety of severe consequences.

The lifetime risk of developing appendicitis is approximately $7 \%$ and usually requires surgical treatment. The overall incidence of this condition is approximately 11 cases per 10,000 populations per year. 
Acute appendicitis may occur at any age, although it is relatively rare at the extremes of age. ${ }^{2} \mathrm{~A}$ male preponderance exists with a male-to-female ratio of $1: 1$ to $3: 1$. The overall lifetime risk is $9 \%$ for males and $6 \%$ for females. A difference in diagnostic error rate ranges from $12 \%$ to $23 \%$ for men and $24 \%-42 \%$ for women. ${ }^{3}$

While the clinical diagnosis may be straightforward in some patients who present with classic signs and symptoms, atypical presentations may lead to diagnostic confusion and delay in treatment. ${ }^{4}$ Abdominal pain is the primary presenting complaint of patients with acute appendicitis. The typical diagnostic sequence of colicky central abdominal pain followed by vomiting with migration of the pain to the right iliac fossa is present in only $50 \%$ of patients to be specific; the patient describes a periumbilical colicky pain, which increases in severity during the first 24 hours, becoming constant and sharp and shifts to the right iliac fossa. The initial pain represents a referred symptom resulting from the visceral innervation of the midgut, and the localised pain is caused by involvement of the parietal peritoneum after progression of the inflammatory process. Loss of appetite is often a predominant feature. Constipation and nausea with profuse vomiting may indicate development of generalized peritonitis after perforation, but it is rarely a major feature in simple appendicitis. ${ }^{5}$

The diagnosis of appendicitis can be challenging even in the most experienced hands and is mostly a clinical one. Accurate anamnesis and physical examination are important to prevent unnecessary surgery and avoid complications. The probability of appendicitis depends on age, clinical setting and symptoms. ${ }^{6,7}$

The mainstay of treatment is an appendectomy and consequently this is one of the most common operations performed on the acute abdomen. ${ }^{8}$ Open Appendectomy (OA) has withstood the test of time for more than a century since its introduction by McBurney.9,10 Since its initial description by Semm in 1983, Laparoscopic Appendectomy (LA) has struggled to prove its superiority over the open technique. ${ }^{9,11}$ It is suggested that laparoscopic removal of an inflamed appendix may have benefits over open surgery. ${ }^{12,13}$ Patients undergoing LA experience a reduction in wound infections, require less intraoperative and postoperative pain medications, stay less time in hospital, have quickened return of normal bowel function and improved cosmetic outcome, avoiding a large laparotomy scar. ${ }^{14}$

Early postoperative pain is the most prevalent and dominant complaint that requires strong analgesia including opiates after elective laparoscopic surgeries. For that reason, many efforts have been made to improve postoperative analgesia, but postoperative pain however does not completely disappear and several studies have shown that visceral pain is the major component. Nonetheless, pain may be moderate to even severe for some patients during the first 24 postoperative hours and has frequently been treated with no steroid anti-inflammatory drugs (NSAIDs) or opioid treatment. 15

The exact aetiology of pain after laparoscopic surgeries is still unclear; however, it appears to be multifactorial and the causes include abdominal wall trauma by trocar entrances, diaphragmatic irritation secondary to $\mathrm{CO} 2$ insufflation and pneumoperitoneum, type and temperature of insufflated gas and intra-abdominal $\mathrm{pH}$, residual intraperitoneal gas, intra-abdominal trauma, microruptures of the parietal peritoneum due to abdominal distension, chemical irritation of the peritoneum, etc. Therefore, multimodal analgesic techniques are necessary. In order to reduce postoperative pain after the laparoscopy, several methods such as rectus cover block, intraabdominal drain placement, intraabdominal instillation of local anaesthetics, intraperitoneal infiltration of the local anaesthetics or opioids, the use of intramuscular morphine injections, patient-controlled analgesia and injection of local anaesthetics into the port sites are suggested. ${ }^{15}$

The pre-emptive intravenous and intraperitoneal application of local anaesthetics is known to improve the postoperative outcome in abdominal surgery. ${ }^{16}$ However, there is lack of consensus regarding the drug, dose, concentration, site and route of administration.

Local administration of tramadol has been found to be an effective analgesic when given intra-articularly or when added to local anaesthetics for nerve blocks. ${ }^{17}$ Tramadol is a synthetic 4-phenyl-piperidine analogue of codeine. It has an affinity for $\mu$-opioid receptors and inhibits the neuronal reuptake of serotonin and norepinephrine. ${ }^{18}$ Tramadol has central analgesic effects due to monoaminergic and $\mu$ receptor agonistic activities. It also has local anaesthetic properties and the risk of serious adverse effects is limited.17,19-21

However, there is scanty data on the effect of intraperitoneal instillation of tramadol alone for the management of immediate postoperative pain in patients undergoing laparoscopic appendicectomy. Further several studies have assessed the role of intraperitoneal instillation of tramadol for the management of immediate postoperative pain in other laparoscopic surgeries and yielded controversial results. The pain in laparoscopic surgery being multifactorial, we chose tramadol as it has multiple mechanism of pain relief as described above. This tempted us to evaluate the role of intraperitoneal instillation of tramadol on postoperative pain relief and emergence of adverse effects following laparoscopic appendectomy.

\section{MATERIALS AND METHODS}

This one year randomized control trial was conducted at Department of General Surgery of tertiary care hospital in North Karnataka from January 2014 to December 2014. The study was approved by Institutional Ethics Committee. Since no similar studies have been reported in the literature on effectiveness of intraperitoneal instillation of tramadol for postoperative pain in laparoscopic appendectomy, applying thumb rule 60 cases undergoing elective laparoscopic appendectomy were included divided into two groups of 30 each. Patients aged 14 years and above, either sex and with ASA grade I and II were included in the study. Uncooperative and unwilling patients. Those with history of anaphylaxis to opioids, immunocompromised patients or severe hepatorenal impairment, ASA grade III, IV and V and those needing conversion to open appendectomy were excluded from the study. Prior to the commencement, the Ethical Clearance was obtained from the Institutional Ethics Committee. Patients fulfilling selection criteria were detailed about the nature of study and a written informed consent was obtained. 
- The demographic data such as age and sex, presenting complaints were noted. The patients were subjected to clinical examination and vitals were noted.

The systemic examination was done and the clinical signs such as RIF tenderness, rebound tenderness and guarding were noted. Their findings were recorded on a predesigned proforma. Patients were divided into two groups of 30 each as group A and B based on computer generated random numbers. Patient placed supine under general anaesthesia. The pneumoperitoneum was created by closed technique (Photograph 2). Trendelenburg with right side up was given during procedure for easy access. The first $10 \mathrm{~mm}$ port was placed in the umbilicus for the 30-degree optical device of size $10 \mathrm{~mm}$ using permanent metallic trocar (Photograph-1). Two other ports were created at suprapubic $(10 \mathrm{~mm})$ and (Photograph 3) right iliac fossa $(5 \mathrm{~mm})$ following trans-illumination of abdominal wall. The surgeon was on the left side of the patient with the first assistant on his right and instrumentation table on lower right side of the patient, while monitor was put on the upper right side of the patient. The operation was performed with five permanent instruments: grasping forceps, curved dissecting forceps, scissors, knot-pusher and specimen retriever. The general anaesthesia protocol remained same for all patients.

Both Group A and Group B patients received intraperitoneal $40 \mathrm{~mL}$ of solution (Drug (Photograph 8)/placebo) prepared by anaesthetist under aseptic precautions, $20 \mathrm{~mL}$ of which was instilled into the subdiaphragmatic space (Photograph 4) and remaining $20 \mathrm{~mL}$ was instilled in right iliac fossa over the appendicular stump and raw area (Photograph 5,6) under direct vision by the surgeon just before removal of trocars.

The instillation was done using metallic suction cannula keeping its knob at irrigation point and syringe nozzle attached to the inlet, while keeping suction outlet closed and secured ensuring no spillage or loss of drug (Photograph 7) Postoperatively, patients were shifted to recovery room, observations were made about outcome variable that is pain requirement of analgesia and complications and recorded by the surgeon, starting immediately after extubation. Both patient and surgeon/assistant were blinded and anaesthetist loaded drug or normal saline according to random table chart and gave it to the surgeon for instillation.

Pain was assessed using Visual Analogue Score (VAS) ranging from 0 to 10 . Visual analogue scale was explained to the patient during pre-operative visit considering 0 as no pain and 10 as maximum pain point. The VAS score $\leq 4$ was regarded as satisfactory, whereas patients reporting VAS score of $>4$ were administered for rescue analgesia with injection Diclofenac sodium $75 \mathrm{mg}$ intramuscularly as a rescue analgesic. Postoperative pain was monitored in terms of VAS scores by the surgeon at 0 minute, 15 minutes, 30 minutes, 60 minutes, 6 hours, 12 hours and 24 hours. Rescue analgesic requirement with $75 \mathrm{mg}$ Diclofenac Sodium was noted immediately postoperative, 15 minutes, 30 minutes, 60 minutes, 6 hours, 12 hours and 24 hours. Incidence of following adverse effects was noted by the surgeon immediately postoperative and at 4, 8, 16 and 24 hour intervals for Nausea, Vomiting, Shoulder pain and Itching.

\section{Statistical Analysis}

The data was entered into the Microsoft Excel Spreadsheet. The data was analysed using SPSS statistical software version 20.0. The categorical data was expressed as rates, ratios and percentages and comparison was done using Fisher's exact test and chi-square test.

Continuous data was expressed as mean \pm standard deviation and the comparison was done using independent sample ' $\mathrm{t}$ ' test. A probability (' $\mathrm{p}$ ' value) of less than or equal to 0.05 at $95 \%$ confidence interval was considered as statistically significant.

\section{RESULTS}

A total of 60 patients undergoing elective laparoscopic appendectomy were divided into two groups of 30 each to as group A and B to receive either intraperitoneal tramadol 150 $\mathrm{mg}$ (Diluted in $40 \mathrm{~mL}$ of normal saline) or $40 \mathrm{~mL}$ of intraperitoneal normal saline.

In the present study, $53.33 \%$ of the patients in group A were males compared to $46.67 \%$ in group B. The male-tofemale ratio in group A was 1.14:1 compared to 1:1.14 in group B. However, the difference was statistically not significant $(p=0.606)$. Most of the patients were aged $\leq 30$ years that is $80 \%$ in group A and $60 \%$ in group B, but the difference was statistically not significant ( $p=0.295) ; 40 \%$ of the patients in group A presented with fever compared to $46.67 \%$ of the patients in group $B(p=0.602)$. All the patients $(100 \%)$ in group A and B presented with abdominal pain $(p=1.000) ; 53.33 \%$ of the patients in group A reported vomiting compared to $56.67 \%$ in group B. However, this difference was statistically not significant $(p=0.795) ; 6.67 \%$ of the patients in group A reported loose stools, while in group B loose stools was noted among $16.67 \%(\mathrm{p}=0.212)$.

RIF tenderness was noted among all the patients $(100 \%)$ in group A and B $(p=1.000) ; 16.67 \%$ of the patients each had rebound tenderness ( $p=1.000$ ); $20 \%$ of the patients in group A had guarding compared to $43.33 \%$ of the patients in group B. However, this difference was statistically not significant ( $\mathrm{p}=0.052) ; 56.67 \%$ of the patients in group A had ASA I status compared to $46.67 \%$ in group B. However, this difference was statistically not significant $(p=0.438)$. Table 1 shows the comparison of mean pulse rate, systolic and diastolic blood pressure, temperature and respiratory rate. However, the vital status of the patients in group A and B did not vary significantly $(\mathrm{p}>0.050)$.

The mean VAS scores at beginning were significantly low in group A $(1.53 \pm 0.94)$ compared to group B $(2.93 \pm 1.17)$ and similar trend was noted at all the durations through the postoperative period $(\mathrm{p}<0.001)$ (Table 2). Most of the patients in group A did not request for the postoperative analgesia $(56.67 \%)$ compared to $6.67 \%$ in group B. This difference was statistically significant $(p=0.011)$ (Table 3). In the present study among the patients with group A, significantly lower number of mean doses was administered $(0.57 \pm 0.82$ vs. $2.20 \pm 0.92 ; \mathrm{p}<0.001)$ compared to group $B$.

The frequency of postoperative rescue analgesia was comparable in group A (3.33\%) compared to B $(10 \%)$ at beginning $(p=0.306)$. Further the frequency of requirement of rescue analgesia was significantly low in group $\mathrm{A}$ at 15 minutes (6.67\% vs. $33.33 \%$; $\mathrm{p}=0.010), 30$ minutes $(6.67 \%$ vs. $36.67 \%$; $=0.005), 6$ hours $(13.33 \%$ vs. $70 \%$; $p<0.001)$ and 12 hours ( $20 \%$ vs. $46.67 \%$; $=0.028$ ) compared to group $B$. 
However, at 60 minutes and 24 hours, the VAS scores were comparable in group A and B ( $>0.050)$ (Table 4). Adverse events were noted in $23.33 \%$ of the patients with group $A$ compared to $10 \%$ in group B. However, this difference was statistically not significant $(\mathrm{p}=0.166)$ (Graph 1$)$.

Among the patients with group A, the frequency of nausea at beginning was $13.33 \%$ and at four hours it was noted in $6.67 \%$ of the patients. In group B, $3.33 \%$ and $6.67 \%$ of the patients had nausea at beginning and at four hours. At 24 hour interval, $3.33 \%$ of the patients in group B reported shoulder pain. However, the frequency of adverse events was comparable in group A and B. (Table 5) The mean hospital stay in group A was significantly low $(3.90 \pm 0.76$ days $)$ compared to group B $(4.47 \pm 1.01$ days $)(p=0.017)$.

\begin{tabular}{|c|c|c|c|c|c|}
\hline \multirow{2}{*}{ Parameters } & \multicolumn{2}{|c|}{ Group A (n=30) } & \multicolumn{2}{|c|}{ Group B (n=30) } & \multirow{2}{*}{ P value } \\
\cline { 2 - 6 } & Mean & SD & Mean & SD & 0.888 \\
\hline Pulse rate (/Minute) & 96.27 & 7.50 & 96.53 & 7.10 & 0.140 \\
\hline Systolic BP (mmHg) & 120.60 & 8.00 & 124.27 & 10.75 & 0.957 \\
\hline Diastolic BP (mmHg) & 74.67 & 5.57 & 74.53 & 12.26 & 0.667 \\
\hline Temperature ( $\mathrm{F}$ ) & 100.25 & 0.78 & 100.34 & 0.88 & 0.643 \\
\hline Respiratory rate (/Min) & 16.77 & 2.82 & 17.07 & 2.12 & \\
\hline \multicolumn{3}{|c|}{ Table 1: Comparison of Vitals } \\
\hline
\end{tabular}

\begin{tabular}{|c|c|c|c|c|c|}
\hline \multirow{2}{*}{ Interval } & \multicolumn{2}{|c|}{ Group A (n=30) } & \multicolumn{2}{c|}{ Group B (n=30) } & \multirow{2}{*}{ P value } \\
\cline { 2 - 6 } & Mean & SD & Mean & 1.17 & $<0.001$ \\
\hline Beginning & 1.53 & 0.94 & 2.93 & 1.30 & $<0.001$ \\
\hline 15 minutes & 2.20 & 1.13 & 3.67 & 2.03 & $<0.001$ \\
\hline 30 minutes & 1.97 & 1.27 & 3.87 & 1.13 & $<0.001$ \\
\hline 60 minutes & 2.10 & 0.84 & 3.37 & 1.27 & $<0.001$ \\
\hline Six hours & 2.07 & 1.57 & 4.37 & 1.27 & $<0.001$ \\
\hline 12 hours & 2.27 & 1.44 & 3.97 & 1.16 & $<0.001$ \\
\hline 24 hours & 1.23 & 1.07 & 2.37 & \\
\hline
\end{tabular}

\begin{tabular}{|c|c|c|c|c|}
\hline \multirow{2}{*}{ Number of Doses } & \multicolumn{2}{|c|}{ Group A (n=30) } & \multicolumn{2}{|c|}{ Group B $(n=30)$} \\
\hline & No. & $\%$ & No. & $\%$ \\
\hline 0 & 17 & 56.67 & 2 & 6.67 \\
\hline 1 & 11 & 36.67 & 3 & 10.00 \\
\hline 2 & 0 & 0.00 & 13 & 43.33 \\
\hline 3 & 2 & 6.67 & 11 & 36.67 \\
\hline 4 & 0 & 0.00 & 1 & 3.33 \\
\hline Total & 30 & 100.00 & 30 & 100.00 \\
\hline & eral & of Anals & & \\
\hline
\end{tabular}

$\mathrm{p}=0.011$

\begin{tabular}{|c|c|c|c|c|c|c|}
\hline \multirow{2}{*}{ Interval } & \multirow{2}{*}{ Requirement } & \multicolumn{2}{|c|}{ Group A $(n=30)$} & \multicolumn{2}{|c|}{ Group B $(n=30)$} & \multirow{2}{*}{$P$ value } \\
\hline & & No. & $\%$ & No. & $\%$ & \\
\hline \multirow[t]{3}{*}{ Beginning } & Yes & 1 & 3.33 & 3 & 10.00 & 0.306 \\
\hline & No & 29 & 96.67 & 27 & 90.00 & \\
\hline & Total & 30 & 100.00 & 30 & 100.00 & \\
\hline \multirow[t]{3}{*}{15 min. } & Yes & 2 & 6.67 & 10 & 33.33 & 0.010 \\
\hline & No & 28 & 93.33 & 20 & 66.67 & \\
\hline & Total & 30 & 100.00 & 30 & 100.00 & \\
\hline \multirow[t]{3}{*}{30 min. } & Yes & 2 & 6.67 & 11 & 36.67 & 0.005 \\
\hline & No & 28 & 93.33 & 19 & 63.33 & \\
\hline & Total & 30 & 100.00 & 30 & 100.00 & \\
\hline \multirow[t]{3}{*}{60 min. } & Yes & 0 & 0.00 & 4 & 13.33 & 0.056 \\
\hline & No & 30 & 100.00 & 26 & 86.67 & \\
\hline & Total & 30 & 100.00 & 30 & 100.00 & \\
\hline \multirow[t]{3}{*}{6 hours } & Yes & 4 & 13.33 & 21 & 70.00 & $<0.001$ \\
\hline & No & 26 & 86.67 & 9 & 30.00 & \\
\hline & Total & 30 & 100.00 & 30 & 100.00 & \\
\hline \multirow[t]{3}{*}{12 hours } & Yes & 6 & 20.00 & 14 & 46.67 & 0.028 \\
\hline & No & 24 & 80.00 & 16 & 53.33 & \\
\hline & Total & 30 & 100.00 & 30 & 100.00 & \\
\hline \multirow[t]{3}{*}{24 hours } & Yes & 2 & 6.67 & 3 & 10.00 & 0.500 \\
\hline & No & 28 & 93.33 & 27 & 90.00 & \\
\hline & Total & 30 & 100.00 & 30 & 100.00 & \\
\hline
\end{tabular}




\begin{tabular}{|c|c|c|c|c|c|c|}
\hline \multirow{2}{*}{ Interval } & \multirow{2}{*}{ Adverse Events } & \multicolumn{2}{|c|}{ Group A (n=30) } & \multicolumn{2}{|c|}{ Group B $(n=30)$} & \multirow{2}{*}{$P$ value } \\
\hline & & No. & $\%$ & No. & $\%$ & \\
\hline \multirow[t]{3}{*}{ Beginning } & Nausea & 4 & 13.33 & 1 & 3.33 & 0.177 \\
\hline & Absent & 26 & 86.67 & 29 & 96.67 & \\
\hline & Total & 30 & 100.00 & 30 & 100.00 & \\
\hline \multirow[t]{3}{*}{4 hours } & Nausea & 2 & 6.67 & 2 & 6.67 & 0.694 \\
\hline & Absent & 28 & 93.33 & 28 & 93.33 & \\
\hline & Total & 30 & 100.00 & 30 & 100.00 & \\
\hline \multirow[t]{3}{*}{8 hours } & Nausea & 0 & 0.00 & 0 & 0.00 & - \\
\hline & Absent & 30 & 100.00 & 30 & 100.00 & \\
\hline & Total & 30 & 100.00 & 30 & 100.00 & \\
\hline \multirow[t]{3}{*}{16 hours } & Nausea & 0 & 0.00 & 0 & 0.00 & - \\
\hline & Absent & 30 & 100.00 & 30 & 100.00 & \\
\hline & Total & 30 & 100.00 & 30 & 100.00 & \\
\hline \multirow[t]{3}{*}{24 hours } & Shoulder pain & 0 & 0.00 & 1 & 3.33 & \\
\hline & Absent & 30 & 100.00 & 29 & 96.67 & 0.500 \\
\hline & Total & 30 & 100.00 & 30 & 100.00 & \\
\hline
\end{tabular}

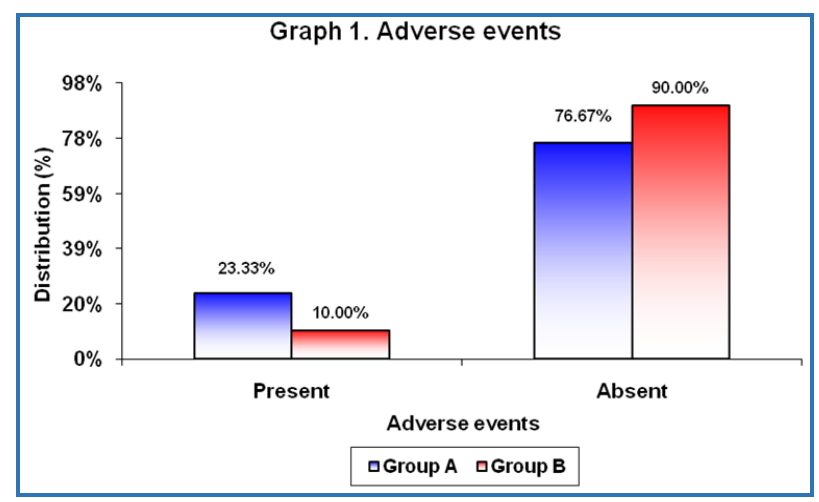

$\mathbf{p}=\mathbf{0 . 1 6 6}$

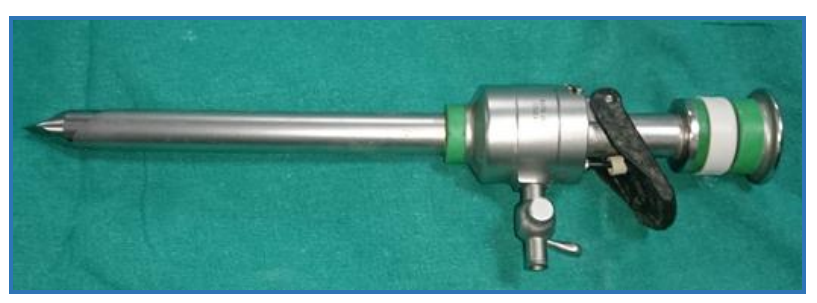

Photograph 1: 10 mm Permanent Metallic Trocar

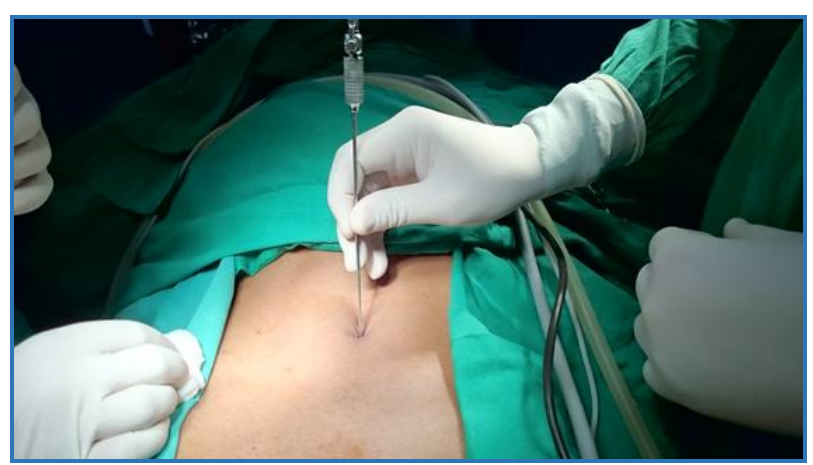

Photograph 2: Creating Pneumoperitoneum using Veress Needle

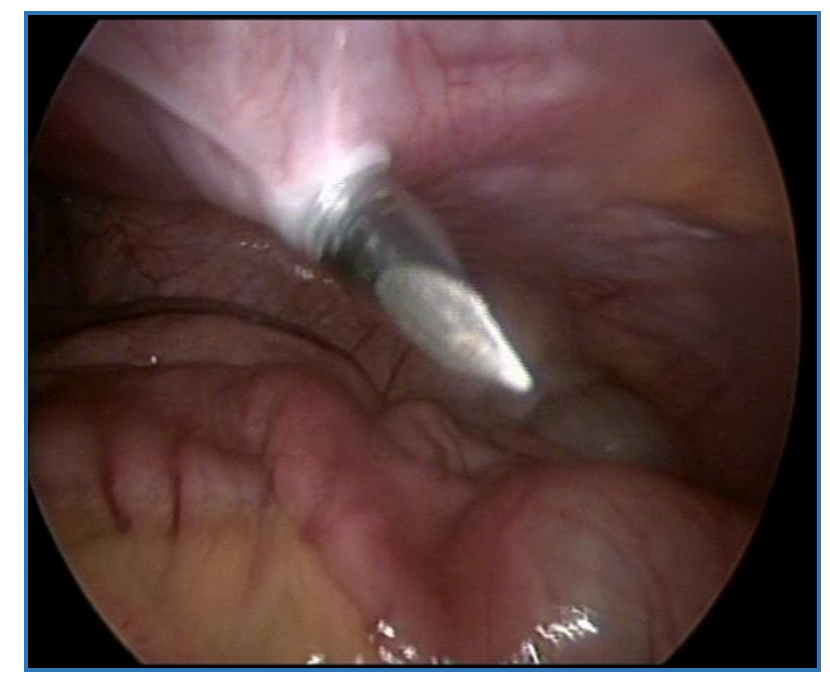

Photograph 3: Insertion of Suprapubic Port under Vision

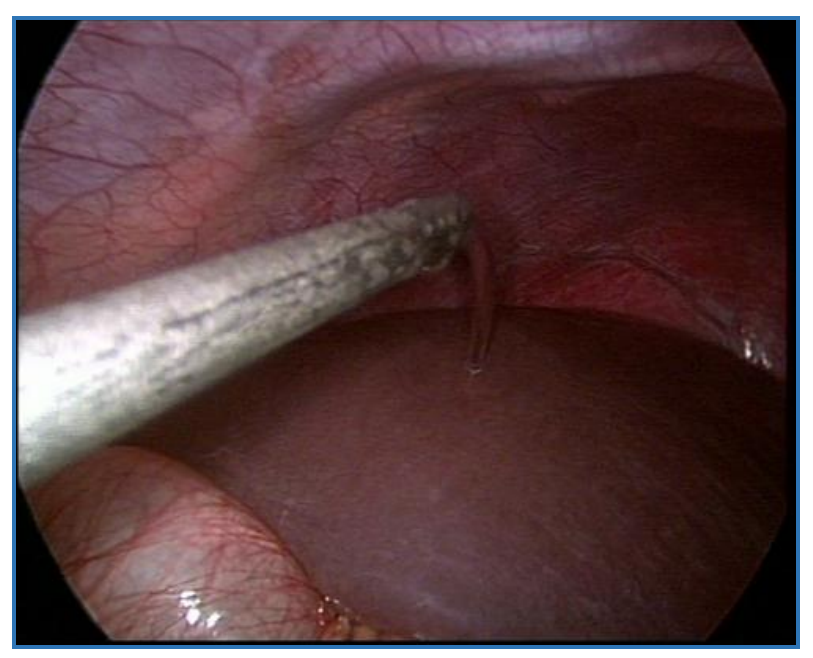

Photograph 4: Instillation of Solution in Right Sub-Diaphragmatic Space 


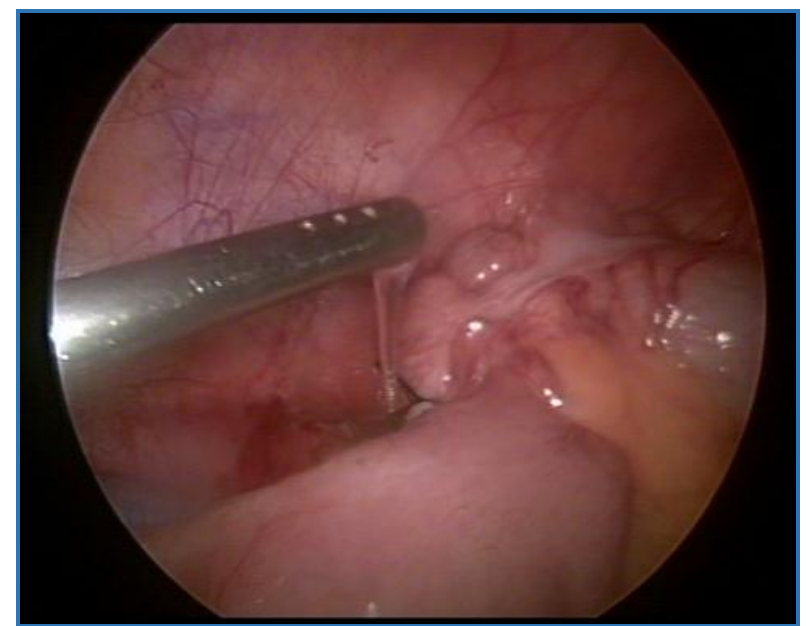

Photograph 5: Instillation of Drug over the Appendicular Stump

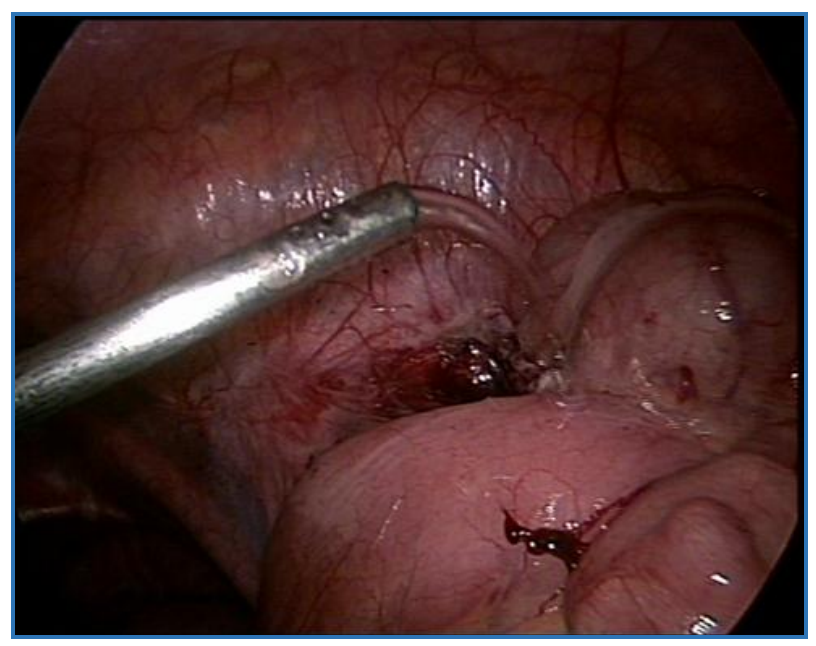

Photograph 6: Instillation of Drug over Raw Area/Appendicular Stump

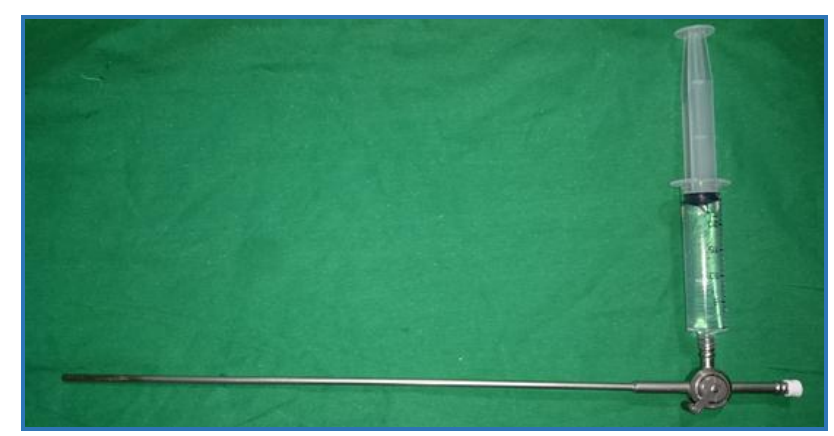

Photograph 7: Metallic Suction Cannula Adjusted for the Instillation of Drug

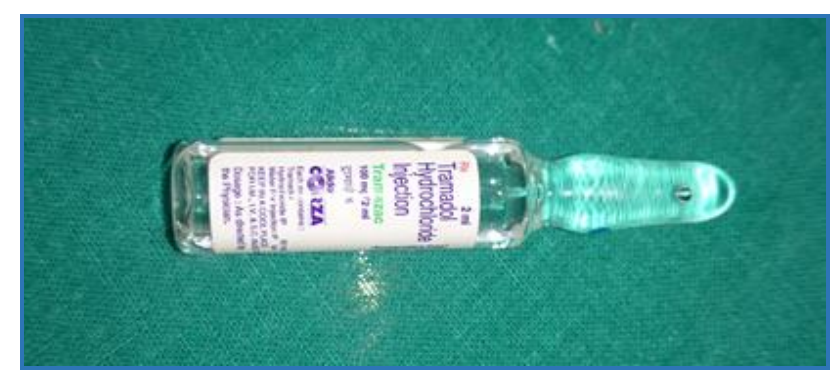

Photograph 8: One Ampule of Tramadol Hydrochloride used in the Study

\section{DISCUSSION}

In the present study, the sex distribution was comparable in group A and group B as $53.33 \%$ in group A and $46.67 \%$ in group $B$ were males. The male-to-female ratio in group $A$ was $1.14: 1$ compared to $1: 1.14$ in group $B(p=0.606)$. In this study the commonest age group was $\leq 30$ years, that is $80 \%$ in group A and $60 \%$ in group B ( $\mathrm{p}=0.295)$. The mean age in group A $(26.13 \pm 9.96$ years $)$ and group $B(31.43 \pm 14.81$ years $)$ were also comparable $(p=0.110)$. These findings suggest that the demographic profile of the study population was comparable in both the groups.

In this study the clinical signs and symptoms including fever $(p=0.602)$, abdominal pain $(p=1.000)$, vomiting $(p=0.795)$, loose stools $(p=0.212)$, RIF tenderness $(p=1.000)$, rebound tenderness $(p=1.000)$ and guarding $(p=0.052)$ were comparable in group $\mathrm{A}$ and $\mathrm{B}$. With regard to anaesthetic characteristics, ASA status was also comparable in group A and $B(p=0.438)$. The clinical examination findings including mean pulse rate, systolic and diastolic blood pressure, temperature and respiratory rate do not vary significantly in patients with group A and B ( $>>0.050)$.

In the present study at beginning, the mean VAS score in group A was $1.53 \pm 0.94$ which increased to $2.20 \pm 1.13$ at 15 minute interval and remained stable in same range at 30 minutes $(1.97 \pm 1.27), 60$ minutes $(2.10 \pm 0.84), 6$ hours $(2.07 \pm 1.57), 12$ hours $(2.27 \pm 1.44)$ and decreased to $1.23 \pm 1.07$. In group B the mean VAS scores at beginning were $2.93 \pm 1.17$, which increased to $3.67 \pm 1.30$ at 15 minutes and peaked at 6 hours with mean VAS score of $4.37 \pm 1.27$ and reduced to $3.97 \pm 1.27$ at 12 hours. The lowest mean VAS score in group B were noted at 24-hour duration $(2.37 \pm 1.16)$. Further, during all the intervals the pain scores in group $A$ remained significantly low compared to group B. These findings suggested that intraperitoneal instillation of $150 \mathrm{mg}$ tramadol diluted in $40 \mathrm{~mL}$ of normal saline offers significant pain relief throughout the postoperative period up to 24 hours with minimum variation compared to normal saline. The effective pain relief observed in group A was reflected by lower consumption of rescue analgesia.

In the present study among the patients in group $\mathrm{A}$, more than half of the study population $(56.67 \%)$ did not request for postoperative analgesia, while $36.67 \%$ of the patients required one dose and only $6.67 \%$ of the patients requested for three doses of rescue analgesia. Whereas, in group B maximum patients that is $43.33 \%$ required two doses, $36.67 \%$ required three doses, $10 \%$ required one dose and only $6.67 \%$ of the patients did not require rescue analgesia. In patients with group $\mathrm{A}$, requirement of rescue analgesia was significantly low at 15 minutes $(6.67 \%$ vs. $33.33 \%$; $\mathrm{p}=0.010$ ), 30 minutes ( $6.67 \%$ vs. $36.67 \%$; $=0.005) 6$ hours $(13.33 \%$ vs. $70 \%$; $p<0.001)$ and 12 hours $(20 \%$ vs. $46.67 \% ; \mathrm{p}=0.010$ ) compared to group B. However, immediate postoperatively $(3.33 \%$ vs. $10 \% ; p=0.306)$ at 60 minutes (None vs. $13.33 \%$; $\mathrm{p}=0.056)$ and 24 hours $(6.67 \%$ vs. $10 \%$; $\mathrm{p}=0.500$ ), the requirement of rescue analgesia did vary significantly.

Also the mean number doses in group $\mathrm{A}$ was significantly low compared to group B $(0.57 \pm 0.82$ vs. $2.20 \pm 0.92 ; \mathrm{p}<0.001)$. The findings show that intraperitoneal instillation of $150 \mathrm{mg}$ tramadol diluted in $40 \mathrm{~mL}$ of normal saline offers not only effective pain relief, but also results in reduction of consumption in rescue analgesia. 
Hence, avoiding discomfort and adverse effects related to repeated intramuscular/intravenous analgesic administration. The frequency of adverse events in group A was slightly high compared to group B, but difference was statistically not significant $(23.33 \%$ vs. $10 \%$; $p=0.166)$. Among the patients with group A, the frequency of nausea and shoulder pain was comparable at all the intervals ( $p>0.050)$. The occurrence of nausea has been observed in early postoperative period in both groups and might be a result of routine side effect of general anaesthesia. These findings suggest that intraperitoneal instillation of $150 \mathrm{mg}$ Tramadol diluted in $40 \mathrm{~mL}$ of normal saline is well tolerated and does not cause significant side effects. Furthermore, the mean hospital stay in group A was significantly low compared to group $B(3.90 \pm 0.76$ vs. $4.47 \pm 1.01$ days; $p=0.017)$. This may be probably due to the better pain relief and early resumption of routine activities by the patient.

Overall, these findings suggest that intraperitoneal instillation of $150 \mathrm{mg}$ Tramadol diluted in $40 \mathrm{~mL}$ of normal saline is well tolerated, offers excellent pain relief, reduces the consumption of rescue analgesia and shortens duration of hospital stay. However, we do not have adequate data to compare these findings due to scanty literature available. Nevertheless, these beneficial effects observed in the present study can be explained by several mechanisms.

Tramadol is a synthetic 4-phenyl-piperidine analogue of codeine. It has an affinity for $\mu$-opioid receptors and inhibits the neuronal reuptake of serotonin and norepinephrine. It is a very weak $\mu$-opioid receptor agonist and its analgesic action depends mainly upon generation of active metabolite (+)-Odesmethyl-tramadol (M1). It also has local anaesthetic properties and local administration of tramadol has been found to be an effective analgesic. 20

Studies have shown adequate absorption of Tramadol from various fibrovascular surfaces of body, achieving adequate blood levels.22

Tramadol provides analgesia by opioid and non-opioid mechanisms. Opioid mechanism involves direct binding to $\mu$ opioid receptors by parent compound and its active metabolites and non-opioid mechanism (Which is local action) involves increase in synaptic levels of two neurotransmitters that is serotonin and norepinephrine. The effect of the non-opioid component of tramadol is through $\alpha$ 2-agonistic and serotoninergic activities, by inhibiting the reuptake of norepinephrine and 5-hydroxytryptamine (Serotonin) and most likely by displacing stored 5hydroxytryptamine from nerve endings. The monoaminergic activity of Tramadol enhances the inhibitory activity of the descending pain pathways resulting in a suppression of nociceptive transmission at the spinal cord level. Tramadol also exerts its sensory blocking action just like a local anaesthetic by blocking the voltage dependent sodium channels and this is the idea exploited behind instillation of tramadol at raw surface/appendicular stump and in subdiaphragmatic space in this study.

Because of its both central and local action, the use of tramadol in this study arises with a thought that it may provide better postoperative pain relief as compared to other drugs having single mechanism of analgesia (Example Bupivacaine and NSAIDS). Most of the previous studies have shown local anaesthetic along with opioids can provide pain relief postoperatively when instilled intraperitoneally, but only scant literature is available on administration of tramadol alone intraperitoneally for postoperative pain relief.

Golubovic S et $\mathrm{al}^{23}$ in 2007 found that intraperitoneal administration of tramadol had valuable implication in reducing VAS score/pain in patients undergoing laparoscopic cholecystectomy.

Another study by Golubonic S. et al24 (2009) who used $50 \mathrm{~mL}$ of saline containing $100 \mathrm{mg}$ of tramadol instilled in peritoneal cavity in laparoscopic cholecystectomy and showed significant reduction in VAS in tramadol group as compared to control (Saline) group at 30 minutes, 1 hour, 2 hours, 4 hours and 6 hours. Mean pain scores in control group were high as compared to tramadol group at all time intervals in first 24 hours.

However, the findings of this study as well as the other studies were contradicted by Akinci et al in 2008.25 who showed that pain scores in control group were less as compared to intraperitoneal tramadol group in first 24 hours postoperatively, but the findings were statistically not significant except at 15 minutes. These findings may be attributed to small sample size of study group in a study by Akinci et al ${ }^{18}$ ( $n=20$ in each group).

Another study done by Hernandes-Pazon et al 26 showed that intraperitoneal administration of local anaesthetic in combination with an opioid reduced the analgesic requirements during first 6 postoperative hours.

Golubovic et $\mathrm{a}^{24}$ in his study concluded that intraperitoneal administration of tramadol and/or bupivacaine is an effective method of management of postoperative pain after laparoscopic cholecystectomy.

Another study by Akinsi et $\mathrm{al}^{25}$ concluded that intravenous tramadol provides superior postoperative pain relief as compared to intraperitoneal administration.

Furthermore, the intraperitoneal local anaesthetics are found to be very effective for the relieving postoperative pain. ${ }^{27}$ This non-invasive method has a minimum risk and it can be easily applied. A similar study. ${ }^{28}$ in PGIMER, Chandigarh, India, on 40 ASA I and II patients of either sex, undergoing laparoscopic cholecystectomy under general anaesthesia in a double blind, randomized controlled manner divided the patients into two groups to receive $20 \mathrm{~mL}$ of normal saline intraperitoneally (Group 1) or $20 \mathrm{~mL}$ of $0.5 \%$ bupivacaine with 1:200,000 adrenaline (Group 2) instilled at the end of surgery in the trendelenburg position. Postoperatively, the patients were assessed for pain scores at $1,4,8,12$ and 24 hours. The VAS was significantly higher in group 1 compared to group 2 at 1 st, 4th and 8th postoperative hour $(\mathrm{P}<0.001 ; \mathrm{p}<0.05)$. Authors concluded that intraperitoneal instillation of bupivacaine causes good pain relief after laparoscopic cholecystectomy.

The longer duration of sustained pain relief in this study in Group A as compared to many other study results of Tramadol in literature, might be attributed to the higher dose of Tramadol used (150 mg).

With the expanding role of ambulatory surgery, the need to facilitate an earlier discharge, improving postoperative discomfort related to pain due to surgery and repeated intramuscular/intravenous analgesia has become an increasingly important issue. The present study showed that single time intraperitoneal instillation of $150 \mathrm{mg}$ tramadol diluted in $40 \mathrm{~mL}$ of normal saline offers excellent pain relief and minimal discomfort and adverse 
effects/complications as compared to those with repeated intravenous/intramuscular analgesia like thrombophlebitis, injection site pain, abscess formation, etc. Hence, reducing need for hospital stay just for analgesia postoperatively while patient is fit to resume routine activities. However, large multicentric studies are required to confirm these findings.

\section{CONCLUSION}

Overall, intraperitoneal instillation of tramadol offers effective postoperative visceral pain relief in laparoscopic appendectomy, while this effect on shoulder pain remains insignificant and needs further evaluation. Further, the incidence of adverse effects like nausea, vomiting, itching and shivering is well acceptable.

\section{REFERENCES}

1. Fitzmaurice GJ, McWilliams B, Hurreiz H, et al. Antibiotics versus appendectomy in the management of acute appendicitis: a review of the current evidence. Can J Surg 2011;54(5):307-14.

2. Hlibczuk V, Dattaro JA, Jin Z, et al. Brown diagnostic accuracy of noncontrast computed tomography for appendicitis in adults. Ann Emerg Med 2010;55(1):51-9.

3. Humes DJ, Simpson J. Acute appendicitis. Br Med J 2006;333:530-4.

4. Birnbaum BA, Wilson SR. Appendicitis at the millennium. Radiology 2000;215(2):337-48.

5. Rybkin AV, Thoeni RF. Current concepts in imaging of appendicitis. Radiol Clin N Am 2007;45(3):411-22.

6. Ebell MH, Athens, Georgia. Diagnosis of appendicitis: part I history and physical examination. Am Fam Physician 2008;77(6):828-30.

7. Howell JM, Eddy OL, Lukens TW, et al. Critical issues in the evaluation and management of emergency department patients with suspected appendicitis. Ann Emerg Med 2010;55(1):71-116.

8. O'Connell PR. The vermiform appendix. In: Williams NS, Bulstrode CJK, O'Connell PR, editors. Bailey and love's short practice of surgery. London (UK): Hodder Arnold, 2008; $25^{\text {th }}$ ed:1204-18.

9. Mohamed A, Bhat N. Acute appendicitis dilemma of diagnosis and management. The Internet J Surg 2009;23(2).

10. McBurney $\mathrm{C}$. The incision made in the abdominal wall in case of appendicitis with a description of a new method of operating. Ann Surg 1894;20(1):38-43.

11. Semm K. Endoscopic appendectomy. Endoscopy 1983;15(2):59-64.

12. Attwood SEA, Hill ADK, Murphy PG. A prospective randomized trial of laparoscopic versus open appendectomy. Surgery 1992;112(3):497-501.

13. McAnena OJ, Austin O, O'Connell PR, et al. Laparoscopic versus open appendicectomy: a prospective evaluation. $\mathrm{Br}$ J Surg 1992;79(8):818-20.
14. Switzer NJ, Gill RS, Karmali S. The evolution of the appendectomy: from open to laparoscopic to single incision. Scientifica Article ID 895469, 2012;2012:5.

15. Memdov C, Mentes O, Simsek A, et al. Comparison of analgesic effects of intraperitoneal lornoxicam and ropivacaine administration in laparoscopic cholecystectomy. Balkan Med J 2010;27:142-9.

16. Kim TH, Kang H, Hong JH, et al. Intraperitoneal and intravenous lidocaine for effective pain relief after laparoscopic appendectomy: a prospective, randomized, double-blind, placebo-controlled study. Surg Endosc 2011;25(10):3183-90.

17. Dayer P, Desmeules J, Collart L. Pharmacology of tramadol. Drugs 1997;53(2):18-24.

18. Grond S, Sablotzki A. Clinical pharmacology of tramadol. Clin Pharmacokinet 2004;43(13):879-923.

19. Robaux S, Blunt C, Viel E, et al. Tramadol added to $1.5 \%$ mepivacaine for axillary brachial plexus block improves postoperative analgesia dose-dependently. Anaesth Analg 2004;98(4):1172-7.

http://www.ncbi.nlm.nih.gov/pubmed?term=Boileau $\% 2$ 0S\%5BAuthor\%5D\&cauthor=true\&cauthor_uid=1504162

20. Altunkaya H, Ozer Y, Kargi E, et al. Comparison of local anaesthetic effects of tramadol with prilocaine for minor surgical procedures. Br J Anaesth 2003;90(3):320-2.

21. Altunkaya H, Ozer Y, Kargi E, et al. The postoperative analgesic effect of tramadol when used as subcutaneous local anaesthetic. Anaesth Analg 2004;99(5):1461-4.

22. Murthy BV, Pandya KS, Booker PD, et al. Pharmacokinetics of tramadol in children after i.v. or caudal epidural administration. $\mathrm{Br} J$ Anaesth 2000;84(3):346-9.

23. Golubović S, Golubović V, Cindrić-Stancin $M$, et al. Intraperitoneal analgesia for laparoscopic cholecystectomy: bupivacaine versus bupivacaine with tramadol. Period Boil 2009;111:263-66.

24. Golubović S, Golubović V, Cindrić-Stancin M, Tokmadzić VS. Intraperitoneal analgesia for laparoscopic cholecystectomy: bupivacaine versus bupivacaine with tramadol. Coll Antropol 2009;33(1):299-302.

25. Akinci SB, Ayhan B, Ayhan IO, et al. The postoperative analgesic efficacy of intraperitoneal tramadol compared to normal saline or intravenous tramadol in laparoscopic cholecystectomy. Eur J Anaesthesiol 2008;25(5):375-81.

26. Hernández-Palazón J, Tortosa JA, Nuño de la Rosa V, et al. Intraperitoneal application of bupivacaine plus morphine for pain relief after laparoscopic cholecystectomy. Eur J Anaesthesiol 2003;20(11):891-6.

27. Inan A, Sen M, Dener C. Local anaesthesia use for laparoscopic cholecystectomy. World J Surg 2004;28(8):741-4.

28. Bhardwaj N, Sharma V, Chari P. Intraperitoneal instillation of bupivacaine for postoperative pain relief after laparoscopic cholecystectomy. Indian J Anaesth 2002;46(1):49-52. 